\title{
A study on the mechanical properties of structure rolled steel and stainless steel for the $\mathrm{CO}_{2}$ welding
}

\author{
Jong Young Lim, Myung Jin Yoon*, Tae Hyun Kim**, Sang Youn Kim** and Tae Gyu Kim***,† \\ Department of Mechanical Engineering, Kyungil University, Gyeongsan 712-701, Korea \\ *Department of Mechanical and Automotive Engineering, Kyungil University, Gyeongsan 712-701, Korea \\ **Department of Nano Fusion Technology, Pusan National University, Miryang 627-706, Korea \\ ***Department of Nanoechatronics Engineering, Pusan National University, Miryang 627-706, Korea
}

(Received August 2, 2013)

(Revised August 9, 2013)

(Accepted August 13, 2013)

\begin{abstract}
It is well known that fatigue failure occur on welded structures in industrial application due to the repetitive load force. In order to decrease the fatigue failure, we analysed the mechanical properties based on their structural aspect, roll steel (SS 400) welded onto stainless steels (STS 304) by $\mathrm{CO}_{2}$ gas as well as structure roll steel welded onto itself. We compared the hardness, tensile and fatigue properties with two kinds of samples which had no defects on the welding part observed by X-ray topographic analysis. It was recognized that the tensile and fatigue strength of SS 400 welded onto itself by $\mathrm{CO}_{2}$ gas was higher than that of SS 400 welded onto STS 304.
\end{abstract}

Key words $\mathrm{CO}_{2}$ welding, X-ray, Tensile and fatigue strength, Rolled and stainless steel

\section{구조용 압연강재와 스테인리스강재의 $\mathrm{CO}_{2}$ 용접에 대한 기계적 특성연구}

\author{
임종영, 윤명진*, 김태현**, 김상윤**, 김태규***,† \\ 경일대학교 대학원 기계공학과, 경산, 712-701 \\ *경일대학교 기계자동차학부, 경산, 712-701 \\ ***부산대학교 나노융합기술학과, 밀양, 627-706 \\ ****부산대학교 나노메카트로닉스공학과, 밀양, 627-706 \\ (2013년 8월 2일 접수) \\ (2013년 8월 9일 심사완료) \\ (2013년 8월 13일 게재확정)
}

요 약 산업시설에는 용접된 구조물에 반복 하중이 발생하여 피로파괴가 발생하고 있는데 이 피로파괴를 줄이기 위해 일반구조용압연강재(SS400)와 스테인리스강 $(\mathrm{STS} 304)$ 을 $\mathrm{CO}_{2}$ 용접하여 기계적 특성 분석을 하였다. X-ray 촬영을 하여 결함 검사를 하고 용접부에 결함이 없는 시험편으로 경도, 인장, 피로 시험을 하였다. 경도는 SS400과 STS304가 용접된 시험편 이 SS304만 용접된 시험편보다 높게 나타났다. 그리고 인장강도와 항복강도는 반대로 SS304만 용접된 시험편이 높았으며 피로한도 또한 마찬가지였다. 따라서 $\mathrm{CO}_{2}$ 용접을 할 경우 융점이 낮고 용접성이 좋은 $\mathrm{SS} 400$ 만으로 용접할 때 더 좋은 성 능을 보여준다.

\section{1. 서 론}

현대 산업에 있어서 용접은 자동차, 건설, 조선 등의 여러 분야에서 구조물 제작에 가장 많이 사용하는 방법 중 하나이다.

\footnotetext{
Corresponding author

Tel: +82-55-350-5282

Fax: +82-55-350-5289

E-mail: tgkim@pusan.ac.kr
}

이들 분야에 널리 사용되는 강은 구조물에 필요한 강 도 범위를 유지하여야 한다. 하지만 용접을 하면 용접부 에 발생하는 높은 열에 의해 기계적 물성변화가 발생하 여 구조물의 안정성이나 수명에 치명적인 영향을 받게 된다. 따라서 이러한 영향을 줄이기 위해서는 사전에 용 접부에 대한 재료의 특성 변화를 알아볼 필요가 있다.

구조용 압연강재인 SS 400 소재는 용접성과 가공성이 우수하고 가격이 저렴하여 기계, 선박용 및 구조물의 주 재료로 많이 사용되고 있고 그 활용도가 매우 높다. 
또한, 스테인리스강은 우수한 성형성, 내식성 및 내열 성을 가지고 있으며 특히 오스테나이트계 스테인리스강 은 기계적 성질이 우수하고, 저온에서 고온에 이르기까 지 광범위한 온도 범위와 다양한 조건에서 폭넓게 사용 되고 있다. 그중 STS 304 소재는 가장 대표적인 스테인 리스강으로 뛰어난 내식성, 내열성, 저온강도를 가지고 있으며, 기계적 성질도 양호하다. 가공성은 크고 열처리 시 경화가 되지 않으며, 자성은 없다. 가정용 식기, 건축 자재, 화학공업, 각종 의료기구, 선박용 부품, 각종 저온 기기 등에 사용한다[1-4].

한편, 산업현장에서 널리 사용되는 플랜트 설비 구조 물은 특정작업 환경에서 오랜 기간 사용 할 목적으로 특 정부위를 다른 재질의 강재나 이종재질을 삽입하여 사용 하는 경우가 많아지고 있다. 또한 기계가공이나 플랜트 배관 등의 구조물을 가진 생산시설에는 대부분 강한진동 이나 소음이 일어난다. 이런 시설에 유체나 미세한 가루 들이 이동하면서 배관의 내 벽면과 마찰이 일어나게 되 고, 특히나 방향을 바꾸어주는 Elbow 부위에는 마찰로 인하여 구멍이 생기는 경우가 발생하게 된다.

이런 Elbow 부위의 수명을 연장하기 위해서 특정부위 를 일반강재보다 내마모성이 우수한 재질로 대처하는 경 우를 볼 수 있다. 그리고 그 특정부위는 스테인리스 재 질을 사용하는 경우가 대부분이며, 기존의 직선부분은 일반강재를 사용하게 되는데 동종용접에 비해 이 두 가 지 재질이 만나는 용접부위는 같은 조건에서 변형, 수축 이 발생되며, 재질의 용융점과 열전도율이 달라 한쪽이 녹지 않을 수 있어 용접결함으로 이어질 수 있다 $[5,6]$.

따라서 본 연구에서는 구조용 압연강재인 SS 400과 스테인리스강인 STS 304에 대해서 $\mathrm{CO}_{2}$ 자동용접을 실 시하여 두 소재간의 용접특성을 조사하고, 용접부의 결 함 등을 조사하기 위하여 X-Ray 방사선투과시험을 실시 하여 용접부와 열영향부를 정밀 조사하였다. 또한, 용접 부의 인장강도, 경도 및 피로수명 등의 기계적 물성 값 을 조사하기 위하여 유압식 피로시험기와 비커스경도시 험을 실시하여 두 소재간의 최적의 용접접합 상태에 따 른 기계적 특성을 조사하였다.

\section{2. 실 험}

\section{1. 실험 재료}

본 연구에 사용된 SS 400 소재의 일반적인 화학적, 기계적 물성 값을 Table 1 및 Table 2와 같다. 또한, STS 304 소재의 화학적, 기계적 물성 값도 Table 3과 Table 4에 나타내었다.

$\mathrm{CO}_{2}$ 용접 시 사용한 용접봉은 고려용접봉에서 생산한
Table 1

Chemical composition of SS 400 (wt.\%)

\begin{tabular}{lllll}
\hline $\mathrm{C}$ & $\mathrm{Si}$ & $\mathrm{Mn}$ & $\mathrm{P}$ & $\mathrm{S}$ \\
\hline- & - & - & 0.05 & 0.05 \\
\hline
\end{tabular}

Table 2

Mechanical properties of SS 400

\begin{tabular}{llll}
\hline & $\begin{array}{l}\text { Yielding strength } \\
\left(\mathrm{N} / \mathrm{mm}^{2}\right)\end{array}$ & $\begin{array}{l}\text { Tensile strength } \\
\left(\mathrm{N} / \mathrm{mm}^{2}\right)\end{array}$ & $\begin{array}{l}\text { Elongation } \\
(\%)\end{array}$ \\
\hline SS400 & 245 & $400 \sim 510$ & 17 \\
\hline
\end{tabular}

Table 3

Chemical composition of STS 304 (wt.\%)

\begin{tabular}{lllll}
\hline $\mathrm{C}$ & $\mathrm{Si}$ & $\mathrm{Mn}$ & $\mathrm{P}$ & $\mathrm{S}$ \\
\hline 0.08 & 1.00 & 2.00 & 0.045 & 0.030 \\
\hline
\end{tabular}

Table 4

Mechanical properties of STS 304

\begin{tabular}{llll}
\hline & $\begin{array}{l}\text { Yielding strength } \\
\left(\mathrm{N} / \mathrm{mm}^{2}\right)\end{array}$ & $\begin{array}{l}\text { Tensile strength } \\
\left(\mathrm{N} / \mathrm{mm}^{2}\right)\end{array}$ & $\begin{array}{l}\text { Elongation } \\
(\%)\end{array}$ \\
\hline STS304 & 205 & 520 & 40 \\
\hline
\end{tabular}

Table 5

Chemical composition of $\mathrm{KC}-28$ for welding material of $\mathrm{CO}_{2}$ (wt.\%)

\begin{tabular}{lllll}
\hline $\mathrm{C}$ & $\mathrm{Si}$ & $\mathrm{Mn}$ & $\mathrm{P}$ & $\mathrm{S}$ \\
\hline 0.08 & 0.50 & 1.05 & 0.014 & 0.010 \\
\hline
\end{tabular}

Table 6

Mechanical properties of $\mathrm{KC}-28$ for welding material of $\mathrm{CO}_{2}$

\begin{tabular}{llll}
\hline & $\begin{array}{l}\text { Yielding strength } \\
\left(\mathrm{N} / \mathrm{mm}^{2}\right)\end{array}$ & $\begin{array}{l}\text { Tensile strength } \\
\left(\mathrm{N} / \mathrm{mm}^{2}\right)\end{array}$ & $\begin{array}{l}\text { Elongation } \\
(\%)\end{array}$ \\
\hline $\mathrm{KC}-28$ & 450 & 550 & 30 \\
\hline
\end{tabular}

$\mathrm{KC}-28$ 솔리드와이어를 사용하였다. 용접봉의 화학적 성 분과 기계적 성질은 Table 5 , Table 6과 같다.

$\mathrm{CO}_{2}$ 용접으로 구조용 압연강과 스테인리스강을 용접 하여 기계적 물성 값의 변화를 비교할 수 있도록 하였다. 용접재의 두께는 $6 \mathrm{~mm}$ 의 평판을 사용하였고, 구속된 상 태에서 자동 용접하여 만들었다. 용접형태는 Fig. 1과 같이 V형 맞대기 아래보기 용접을 실시하여 재현성을

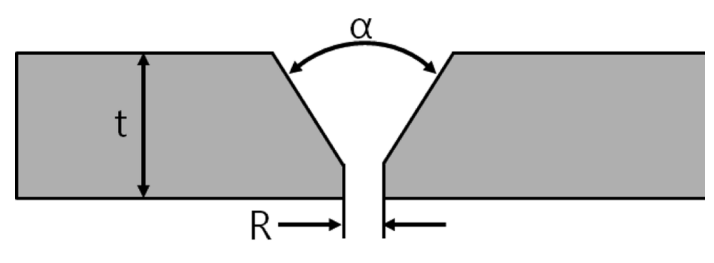

$$
\text { ( } a: 60^{\circ} \pm 5^{\circ} \mathrm{t}: 6 \mathrm{~mm} \quad \mathrm{R}: 3 \mathrm{~mm} \text { ) }
$$

Fig. 1. Shape and dimensions of V groove for weld. 
Table 7

Welded specimens

$\begin{array}{ll}\text { Sample } 1 & \mathrm{SS} 400-\mathrm{CO}_{2}-\mathrm{SS} 400 \\ \text { Sample } 2 & \mathrm{SS} 400-\mathrm{CO}_{2}-\mathrm{STS} 304\end{array}$

Table 8

Welding conditions

\begin{tabular}{llll}
\hline $\mathrm{CO}_{2}$ welding & $\begin{array}{l}\text { Current } \\
(\mathrm{A})\end{array}$ & $\begin{array}{l}\text { Volt } \\
(\mathrm{V})\end{array}$ & $\begin{array}{l}\text { Speed } \\
(\mathrm{mm} / \mathrm{sec})\end{array}$ \\
\hline First & 100 & 20 & 8 \\
Second & 120 & 21 & 8 \\
\hline & $\begin{array}{l}\text { Weave speed } \\
(\mathrm{mm} / \mathrm{sec})\end{array}$ & $\begin{array}{l}\text { Weave range } \\
(\mathrm{sec})\end{array}$ & $\begin{array}{l}\text { Stay time } \\
(\mathrm{sec})\end{array}$ \\
\hline First & - & - & - \\
Second & 2 & 1.5 & 0.7 \\
\hline
\end{tabular}

갖도록 하였다.

사용한 용접기는 $\mathrm{BEAM}-350$ 이고, 이 용접기는 $\mathrm{CO}_{2}$, $\mathrm{MIG}, \mathrm{MAG}$ 용접을 할 수 있는 용접기다. 또한, 이 용접 기에는 전류, 전압, 주행속도, 위빙 폭, 위빙속도, 좌·우 멈춤을 조정할 수 있는 기능을 가지고 있다.

용접은 1차 용접과 2차 용접으로 나누어 $\mathrm{V}$ 형 용접 부 를 채웠다. 1차 용접시 이면을 보호하기 위해 ceramic backing을 부착하여 용접하였고, 용접 조건은 Table 8과 같다.

\section{2. $\mathrm{CO}_{2}$ 용접}

$\mathrm{CO}_{2}$ 용접은 탄산가스 아크 용접이라고도 하며, GMAW 용접의 일종으로 차폐가스로 $\mathrm{CO}_{2}$ 가스를 이용한다. 일 반탄소강과 저합금강의 용접에 널리 이용된다. $\mathrm{CO}_{2}$ 용 접법은 아르곤, 헬륨 등의 비싼 불활성 가스를 사용한 $\mathrm{TIG}, \mathrm{MIG}$ 용접에 비해 저렴하나 스패터와 슬래그의 발 생이 많고, 비드외관이 미려하지 못한 단점이 있다. 그러 나 용접부의 용입이 우수하고, 고속으로 튼튼한 용접을 할 수 있는 장점을 가지고 있다[7].

\section{3. 실험방법}

\subsection{1. $\mathrm{X}$ 선 촬영}

실험에 앞서 용접의 정상유무를 파악하기 위해 방사선 투과시험을 하여 용접부의 결함유무를 파악하였다. 방사 선투과검사 장비(Radiographic Inspection; RF-250EGM, Rigaku)를 사용하여 방사선투과시험을 실시하였다.

\subsection{2. 경도시험}

경도측정은 미소 경도계(Micro-Vickers Hardness Tester; HM-101, Mitutoyo)를 이용하여 4가지 시험편의 용착부

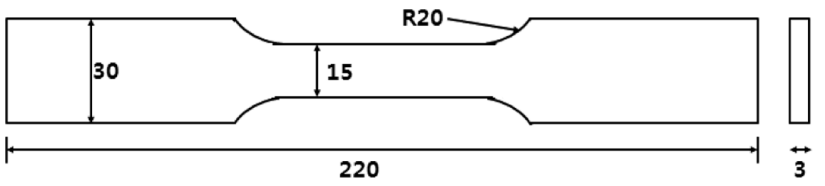

Fig. 2. specimen of tensile test.

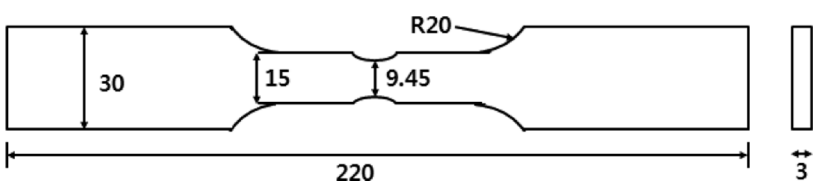

Fig. 3. Specimen of fatigue test specimen.

를 $500 \mathrm{~g}$ 의 하중으로 중심에서 $2 \mathrm{~mm}$ 씩 좌, 우로 4구간 과 양쪽 모재부를 10 회 측정한 후, 최대 및 최소값을 제 외한 나머지 값들의 평균값을 구하였다.

\subsection{3. 인장시험}

인장시험편은 용접된 재료를 $\mathrm{ASTM}$ 의 규격에 따라 Fig. 2와 같이 표준 인장시험편으로 가공하였고, 중앙부 에 용착부, 열영향부, 모재부가 각각 위치하도록 하였다 [8].

용착부를 포함한 시험편의 인장특성평가를 위하여 유 압식 만능재료시험기(Servo hydraulic fatigue testing machine; Model 8516, INSTRON)로 최대 용량은 10 ton인 장비를 사용하였다.

\subsection{4. 피로시험}

용접부의 피로수명 및 피로한도를 평가하기위해서 시 험편을 ASTM 규격에 의거하여 제작하였고, Fig. 2의 인장시험편과 마찬가지로 중앙부에 용착부, 열영향부, 모 재부가 위치하도록 하였다[9].

본 시험에 사용된 시험기는 정적인장시험기와 같은 시 험기로 응력비 $\mathrm{R}=0.1$, 하중반복속도는 $10 \mathrm{~Hz}$, 인장-인 장형태 정형파형으로 시험하였다.

\section{3. 결과 및 고찰}

\subsection{X-Ray 조사}

용접된 시험편의 결함유무를 파악하기 위해 가장 편리 하고 널리 사용되는 X-Ray 방사선 투과시험을 실시하였 다. 그 결과 동종용접의 경우 그 금속에 맞는 충분한 용 접을 선택하여 용접을 하였기 때문에 큰 결함은 발생하 지 않는 경우가 대부분이다. 하지만 이종용접의 경우는 균열, 기공, 언더컷, 오버랩 등의 쉽게 발생됨을 확인하 였다. Fig. 4는 본 연구에서 사용한 용접부 시험편의 X- 

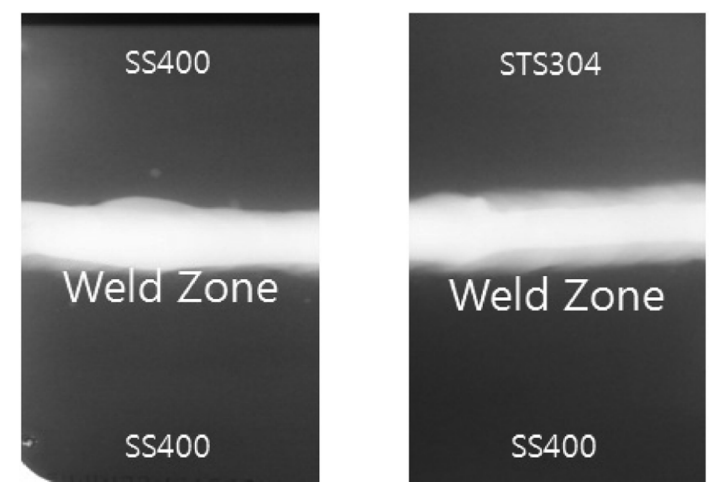

Fig. 4. Radiography film.

Ray 방사선 투과시험 용접시험편으로서 용접부에 결함 이 발생하지 않음을 확인하였다.

\section{2. 경도시험}

Table 9, 10 및 Fig. 5는 본 실험에 사용한 SS 400과 STS 304 소재의 비커스경도 값을 측정하여 나타낸 것이 다. 두 소재의 용착부, 열영향부, 모재부의 경도 값을 $2 \mathrm{~mm}$ 일정 간격으로 측정하여 그 결과를 비교 분석하였 다. 이 경도 측정을 통해서 SS 400소재 보다 STS 304 소재의 경도가 높음을 확인하였고, 용착부와 열영향부,

Table 9

Vickers hardness values according to a distance of sample 1

\begin{tabular}{llllllllllll}
\hline $\mathrm{mm}$ & -10 & -8 & -6 & -4 & -2 & 0 & 2 & 4 & 6 & 8 & 10 \\
\hline $\mathrm{Hv}$ & 144 & 136 & 154 & 186 & 188 & 188 & 191 & 189 & 173 & 129 & 129
\end{tabular}

Table 10

Vickers hardness values according to a distance of sample 2

\begin{tabular}{llllllllllll}
\hline $\mathrm{mm}$ & -10 & -8 & -6 & -4 & -2 & 0 & 2 & 4 & 6 & 8 & 10
\end{tabular}

\begin{tabular}{llllllllllll}
\hline $\mathrm{Hv}$ & 147 & 135 & 156 & 187 & 188 & 190 & 208 & 218 & 225 & 225 & 224
\end{tabular}

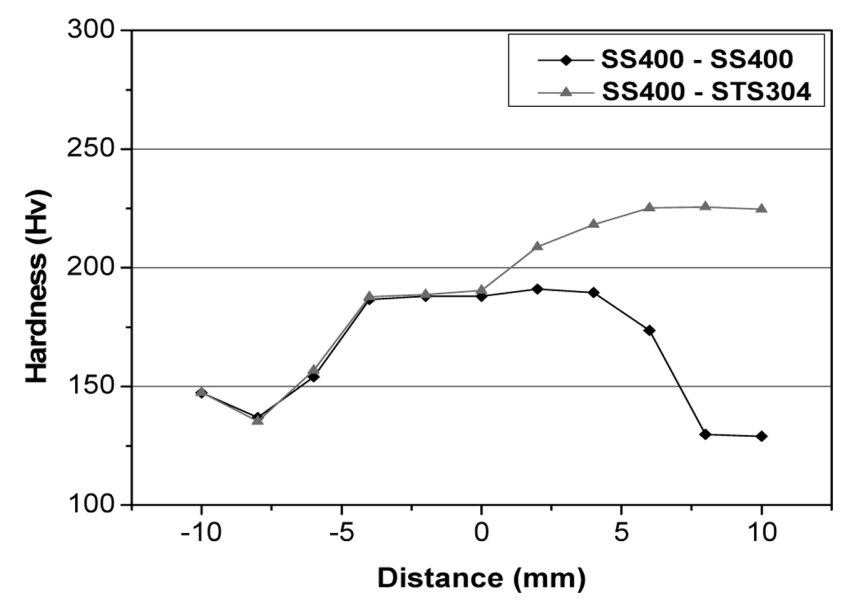

Fig. 5. Vickers hardness for measurement distance.

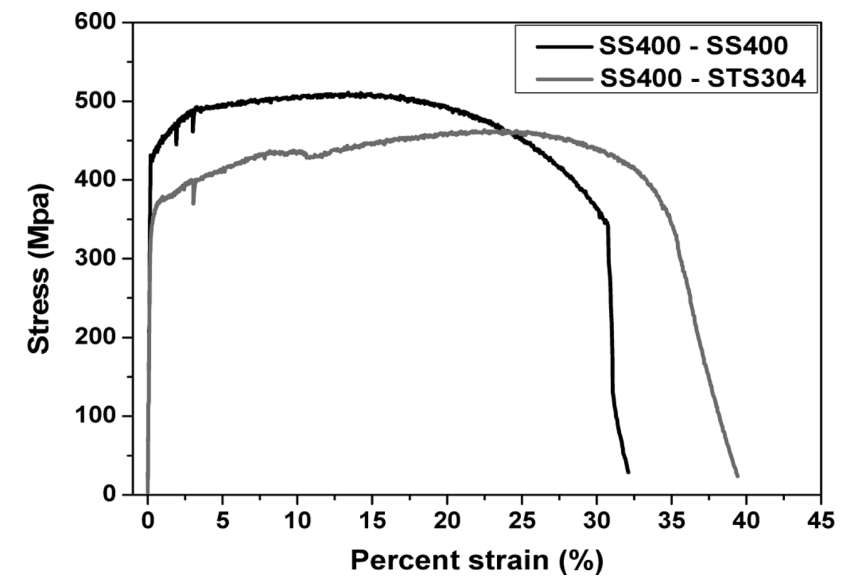

Fig. 6. Stress-strain curve of welded specimen.

Table 11

Results of tensile test

\begin{tabular}{lllll}
\hline Specimen & $\begin{array}{l}\text { Tensile } \\
\text { strength } \\
(\mathrm{MPa})\end{array}$ & $\begin{array}{l}\text { Yieding } \\
\text { strength } \\
(\mathrm{MPa})\end{array}$ & $\begin{array}{l}\text { Young's } \\
\text { modulus } \\
(\mathrm{MPa})\end{array}$ & $\begin{array}{l}\text { Elongation } \\
(\%)\end{array}$ \\
\hline SS400-SS400 & 511.2 & 429.7 & 246,800 & 33.45 \\
SS400-STS304 & 463.4 & 353.0 & 248,900 & 39.88 \\
\hline
\end{tabular}

모재부의 경도 값을 비교 했을 때 용착부의 경도 값이 모재부에 비해 높았으며, 열영향부와 모재부는 비슷한 경도 값을 나타냈다.

\section{3. 인장시험}

$\mathrm{SS} 400$ 인 동종 소재와 SS 400과 STS 304 이종소재 간의 용접시험편을 $\mathrm{CO}_{2}$ 자동용접기로 용접한 시험편에 대해서 정적 인장시험을 실시하였다. 인장시험은 $1 \mathrm{~mm} /$ $\min$ 하중제어방식으로 실험을 실시하였다. 그 시험결과 Fig. 6과 같이 용접성이 우수한 SS 400인 동종 용접시험 편이 인장강도가 SS 400소재와 STS 304 소재가 용접된 이종 시험편보다 $50 \mathrm{MPa}$ 정도 더 높게 나타남을 알 수 있었고, 그 시험결과를 Fig. 6과 Table 11에 각각 나타내 었다. 한편, SS 400과 STS 304 소재간의 이종 용접시험 편은 SS 400 동종 소재간의 용접시험편보다 인장강도는 약간 낮으나 상대적으로 연신율이 큰 STS 304의 영향으 로 연신율은 약 $6 \%$ 증가한 것으로 나타났다.

\section{4. 피로시험}

피로시험은 정적인장시험에서 사용한 시험편인 SS 400 인 동종 소재와 SS 400과 STS 304 이종소재간의 $\mathrm{CO}_{2}$ 용접시험편을 사용하여 피로시험을 실시하였다. 실험조 건으로는 응력비 $\mathrm{R}=0.1$ 인 인장-인장 정현파 형태로 하 중을 부가하여 시험편이 완전 파단 될 때 까지 실시하였 


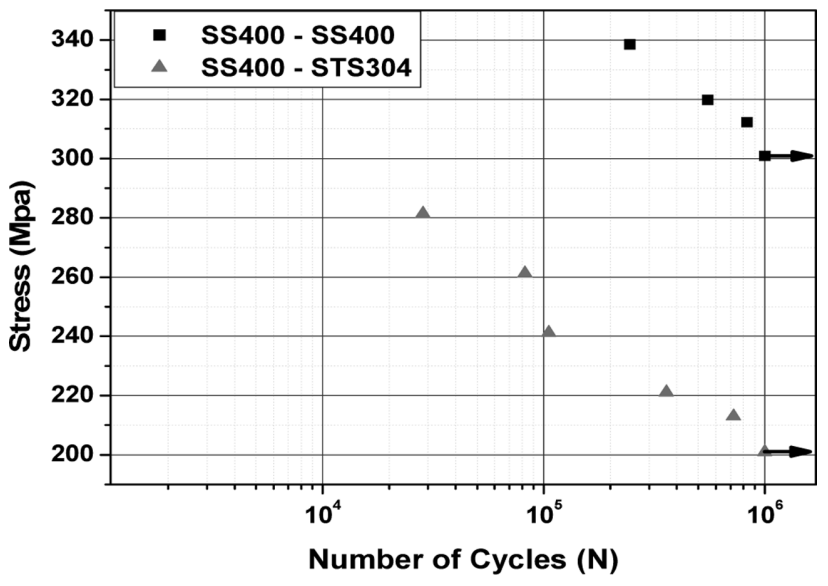

Fig. 7. Relationship between stress and number of cycle to failure.

다. 피로시험 결과는 Fig. 7에 나타내었다.

피로시험 결과, 인장강도가 높았던 SS 400인 동종 소 재간의 용접시험편이 SS 400과 STS 304 이종 소재간 의 용접시험편보다 약 $100 \mathrm{MPa}$ 이상 높은 피로강도 값 을 나타냄을 알 수 있었다. 이종소재간의 $\mathrm{CO}_{2}$ 용접시험 편의 피로강도가 동종 소재에 비해서 월등하게 낮아지는 원인은 $\mathrm{CO}_{2}$ 용접에서 발생하는 고열의 냉각으로 인한 이종 소재간의 잔류응력의 영향으로 피로강도 급격하게 낮아지는 것으로 판단되어진다. 또한 STS 304 소재는 SS 400 소재보다 용융점이 높기 때문에 용접 시 용접봉 의 용융금속과 STS 304 소재가 완전 용해되지 않은 것 과 Fig. 5에 나타난바와 같이 이종 소재간의 급격한 경 도값의 변화도 피로강도를 저하시키는 요인으로 추측할 수 있다[10].

따라서 이종재료간의 피로강도를 향상시키기 위해서는 용접 후 잔류응력 제거를 위한 풀림처리 또는 쇼트피닝 등 후처리가 필요 할 것으로 판단되고, 용접시 용접봉 소재와 STS 304 소재간의 완전 용해를 위한 적정 용접 가열온도의 확립이 필요할 것으로 판단된다.

Fig. 8은 SS 400과 STS 304 이종 소재간 $\mathrm{CO}_{2}$ 용접 시험편을 피로시험한 결과이다. 피로균열은 SS 400 소재 의 열영향부에서 파괴가 진행되었고, 피로파면을 전계방 사형 주사전자현미경(Field Emission Scanning Electron Microscopy; S4700, Hitachi, Japan)으로 분석하였다. Fig. 8의 (a)에 일정한 간격의 striation이 나타나고 있음 을 알 수 있다. 이것은 하중이 증가함에 따라서 균열 끝 에서 소성변형이 많이 일어나고, 인장응력이 걸릴 때 균 열이 전파되고 새로이 생기는 파면이 대기 중에서 고온 산화가 일어난다. 그리고 압축응력이 걸릴 때 산화된 파 면이 융착 되지 않기 때문에 뚜렷하고 규칙적인 striation 이 발생된다. 이것은 진공중의 피로파면과 비교해 봄으 로서 잘 알 수 있다. striation이 없어지는 부분에서 Fig.
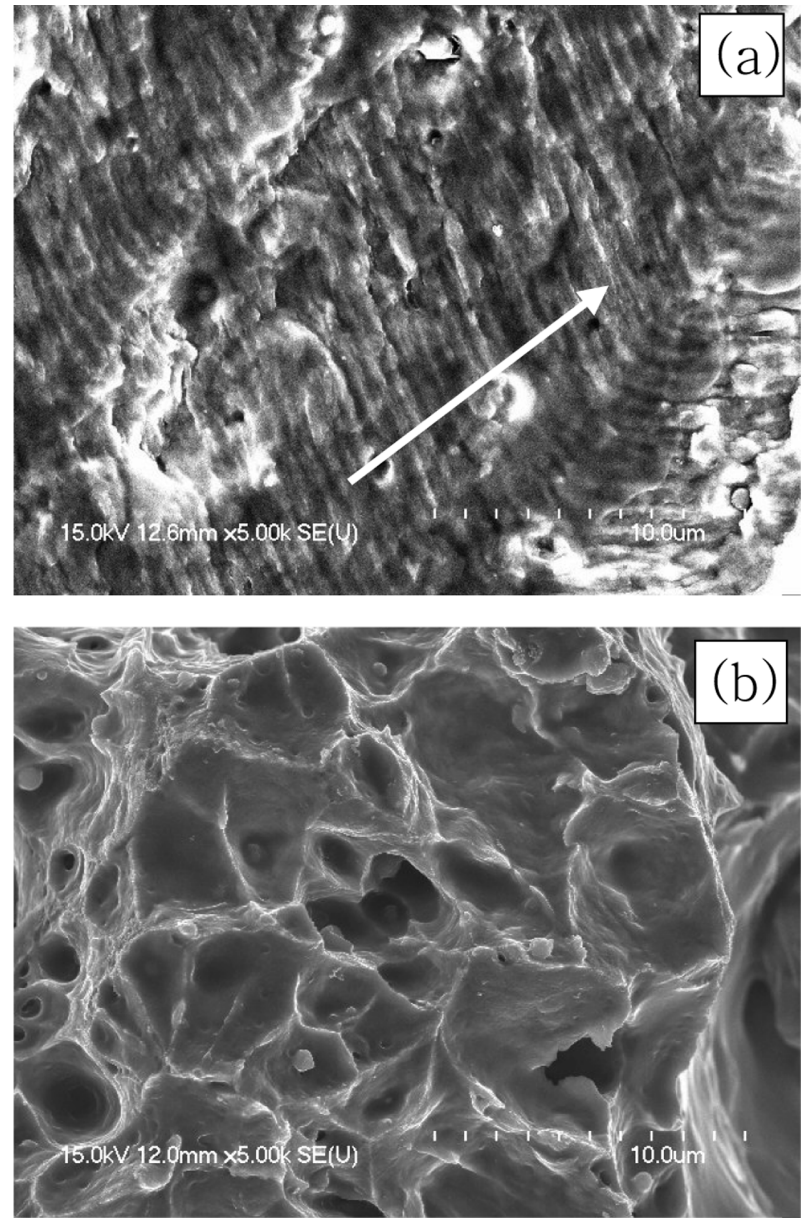

Fig. 8. SEM images of the fatigue fracture surface for the weld specimen.

8의 (b)에 나타낸 것 과 같은 dimple 파괴가 일어났다. 최초 균열이 발생되고 취성파괴, 연성 striation, dimple 파괴의 순서로 전 파괴과정이 입내파괴의 양상으로 나타 나고 있음을 알 수 있다.

\section{4. 결 론}

본 연구는 SS 400 인 동종 소재와 SS 400과 STS 304 소재간의 이종 소재간의 $\mathrm{CO}_{2}$ 용접 시 용접특성과 기계적 물성특성을 조사하기 위한 실험연구를 수행하였 고, 그 결과 다음과 같은 결론을 얻었다.

1) $\mathrm{SS} 400$ 인 동종 소재간의 용접시험편과 SS 400과 STS 304 이종 소재간의 용접시험편의 비커스 경도변화 는 동종 소재에서는 용착부와 열영향부가 모재부보다 높 은 경도값을 나타내었고, SS 400 소재와 STS 304 이종 소재간의 용접에서는 STS 304의 용착부와 열영향부가 SS 400 소재와의 용접영향으로 상대적으로 낮은 경도값 이 나타났다. 
2) $\mathrm{SS} 400$ 인 동종 소재의 인장시험 결과는SS 400과 STS 304 이종 소재가 용접된 시험편보다 약 $50 \mathrm{MPa}$ 더 높게 나타났으나 연신율은 약 $6 \%$ 낮게 타나났다.

3) 피로시험 결과 SS 400과 STS 304로 용접된 이종 시험편은 SS 400의 동종 소재 시험편 보다 $100 \mathrm{MPa}$ 이상 낮은 피로강도를 나타내었는데 용접후의 잔류응력 제거나 최적용접조건, 용접후처리 공정 등의 연구가 선 행되어야 할 것으로 판단된다.

\section{참 고 문 헌}

[1 ] R.-J. Wang and D.-G. Shang, "Fatigue life prediction based on natural frequency changes for spot welds under random loading", J. of Fatigue 31 (2009) 361.

[2 ] K. Iida and Y. Yazaki, "The bending fatigue strength of welded steel pipe with uniform mismatch", J. of Pressure Vessels and Piping 3 (1975) 211.

[ 3 ] H.T. Kang, P. Dong and J.K. Hong, "Fatigue analysis of spot welds using a mesh-insensitive structural stress approach", J. of Fatigue 29 (2007) 1546.

[4] I. Poutiainen and G. Marquis, "A fatigue assessment method based on weld stress", J. of Fatigue 28 (2006) 1037.

[ 5 ] J.K. Hong, J.H. Park, N.K. Park, I.S. Eom, M.B. Kim and C.Y. Kang, "Microstructures and mechanical properties of Inconel 718 welds by $\mathrm{CO}_{2}$ laser welding", J. of Materials Processing Technology 201 (2008) 515.

[6] L.W. Tsay, C.L. Hsu and C. Chen, "Notched tensile fracture of Ti-4.5Al-3V-2Fe-2Mo welds at elevated temperatures", J. of Materials Chemistry and Physics 120 (2010) 715.

[7] L.W. Tsay and C.Y. Tsay, "The effect of microstructures on the fatigue crack growth in Ti-6Al-4V laser welds", J. of Fatigue 19 (1997) 713.

[ 8 ] ASTM E8, "Standard Test Methods for Tension Testing of Metallic Materials", ASM INTERNATIONAL 8 (1990).

[9] ASTM E466, "Standard Practice for Conducting Force Controlled Constant Amplitude Axial Fatigue Tests of Metallic Materials", ASMINTERNATIONAL 8 (1990).

[10] D.J. Lee, J.C. Byun, J.H. Sung and H.W. Lee, "The dependence of crack properties on the $\mathrm{Cr} / \mathrm{Ni}$ equivalent ratio in AISI 304L austenitic stainless steel weld metals", J. of Materials Science and Engineering 513 (2009) 154. 